\title{
Gestational nutrition 2: gene expression in sheep fetal ovaries exposed to gestational under nutrition
}

\author{
Peter Smith ${ }^{1,2}$, Jennifer Juengel ${ }^{2}$, Paul Maclean ${ }^{3}$, Christy Rand ${ }^{1}$ and Jo-Ann L Stanton ${ }^{1}$ \\ ${ }^{1}$ Department of Anatomy, University of Otago, Dunedin, New Zealand, ${ }^{2}$ Animal Science, AgResearch, Invermay \\ Agricultural Centre, Mosgiel, New Zealand and ${ }^{3}$ Bioinformatics and Statistics, AgResearch, Lincoln Research Centre, \\ Christchurch, New Zealand \\ Correspondence should be addressed to P Smith; Email: peter.smith@agresearch.co.nz
}

\begin{abstract}
A number of studies have demonstrated effects of gestational undernutrition on fetal ovarian development and postnatal female fertility. However, the mechanism underlying these effects remains elusive. Using a cohort of animals in which altered gestational nutrition affected indicators of postnatal fertility, this study applies RNAseq to fetal ovaries to identify affected genes and pathways that may underlie the relationship between gestational plane of nutrition and postnatal fertility. Pregnant ewes were exposed to either a maintenance diet or 0.6 of maintenance for the first 55 days of gestation followed by an ad libitum diet. Complementary DNA libraries were constructed from 5 to 6 fetal ovaries from each nutritional group at both days 55 and 75 of gestation and sequenced using Ion Proton. Of approximately 16,000 transcripts, 69 genes were differentially expressed at day 55 and 145 genes differentially expressed at day 75. At both gestational ages, genes expressed preferentially in germ cells were common among the differentially expressed genes. Enriched gene ontology terms included ion transport, nucleic acid binding, protease inhibitor activity and carrier proteins of the albumin family. Affected pathways identified by IPA analysis included LXR/RXR activation, FXR/RXR activation, pathways associated with nitric oxide production and citrullination (by NOS1), vitamin C transport and metabolism and REDOX reactions. The data offer some insights into potential mechanisms underlying the relationship between gestational plane of nutrition and postnatal fertility observed in these animals. In particular, the roles of nitric oxide and protease inhibitors in germ cell development are highlighted and warrant further study.

Reproduction (2019) 157 13-25
\end{abstract}

\section{Introduction}

The effects of gestational nutrition on fetal ovarian development and subsequently the effects on fertility in female offspring have been studied in a range of species, with sheep being a popular model for these studies. Previous studies in sheep have shown restricted gestational nutrition affects fetal ovarian development by decreasing fetal ovarian weight (Rae et al. 2001, Grazul-Bilska et al. 2009), decreasing germ cell proliferation (Lea et al. 2006) and germ cell number (Rae et al. 2001), increasing primordial follicle number and decreasing numbers of growing follicles (Rae et al. 2001). Conversely, overfeeding sheep during gestation has been shown to affect fetal ovarian development by increasing follicle numbers (Da SilvaButtkus et al. 2003, Asmad et al. 2015) and increasing germ cell numbers (Borwick et al. 1997). Regardless of whether gestational plane of nutrition was above or below maintenance levels, impacts on the ovaries of female offspring have been reported (Rae et al. 2002, Kotsampasi et al. 2009, Long et al. 2010). These impacts had predominantly negative effects on fertility of the offspring (Gunn et al. 1995, Rae et al. 2002, Long et al. 2010).

The mechanism(s) underlying the effects of gestational nutrition on fetal ovarian development and/or adult female fertility are yet to be established. Potential mechanisms including nutrient delivery, endocrine status, changes to the reproductive axis and gene expression are broadly outlined by Rhind et al. (2004). However, given the relationship between establishment of the ovarian reserve, antral follicle count and fertility (Broekmans et al. 2006, Ireland et al. 2008, 2010), it seems logical that potential mechanisms during ovarian development are likely to target germ cell development. Increased germ cell DNA damage has been reported in fetal ovaries exposed to restricted gestational nutrition (Murdoch et al. 2003) and offers one mechanism by which restricted gestational nutrition may affect fetal ovarian development and subsequently the fertility of female offspring.

There is a paucity of data examining how changes in maternal nutrition may affect the fetal ovarian transcriptome and the implications of altered gene expression on ovarian development. While some studies 
have focused on key genes involved in development (Da Silva et al. 2003), few have examined the whole transcriptome. Costa used RNAseq to examine changes in the fetal ovarian transcriptome at day 60 of gestation from cows on a restricted nutrition regime. Differential expression of 79 genes (from a total of 20,000) was noted with some of these genes involved in embryonic or ovarian development (Costa et al. 2014). Lea used microarray to examine gene expression in fetal ovaries where maternal ewes were exposed to sewage sludge for a range of periods during gestation (Lea et al. 2016). Between 4 and 120 transcripts were differentially expressed depending on the exposure time. Differentially expressed transcripts were involved in functions such as cell growth and differentiation, cell cycle regulation, cell death, cell differentiation and cell movement.

In a companion paper (ref companion paper), restricted gestational nutrition in sheep from day 0 to 55 , followed by ad libitum feeding, resulted in alterations to fetal ovarian development, and surprisingly, increased indicators of fertility in female offspring. To examine potential mechanisms underlying the effects of gestational nutrition in this model, RNAseq was performed to examine gene expression patterns in fetal ovaries from the same cohort of animals described in the companion paper.

\section{Materials and methods}

\section{Animal model}

All animal manipulations were carried out in accordance with the 1999 Animal Protection (Codes of Ethical Conduct) Regulations of New Zealand and were approved by the Invermay Agricultural Centre Animal Ethics Committee (AE13294, 13098 and12820).

Details of animals and diets have been described previously (ref companion paper). Briefly, on the second cycle following synchronization, 79 five-year-old Romney $\times$ Coopworth ewes were mated to intact Texel rams. From the day of mating, ewes were housed indoors with 39 ewes fed a maintenance diet (comprising sheep pellets, chaff and silage) and 40 ewes were fed a diet equivalent to 0.6 of maintenance based on metabolizable energy intake. For maintenance ewes, this was calculated at 14.5 megajoules of metabolizable energy per day (using the formula $0.6 \times$ ewe weight $(\mathrm{kg})^{0.75}$, supplied by the AgResesearch Small Ruminant Research Unit, Palmerston North, NZ). Those ewes on 0.6 maintenance diet received 8.7 megajoules per day. At day 55 of gestation, ewes were then fed ad libitum pasture. A subgroup of these ewes $(n=23)$ were assigned for fetal collections. Following a barbiturate overdose, female fetuses were recovered at day 55 and 75 . The right ovaries of fetuses from unique dams were weighed, snap frozen in liquid nitrogen and stored at $-70^{\circ} \mathrm{C}$ until required for RNA extraction $(n=6$ maintenance and six restricted at day 55 and $n=6$ maintenance and five restricted at day 75 ).

\section{RNA extraction}

RNA extractions were performed using the Zymo duet kit (Zymo Research Corporation, Irving, CA, USA. Cat D7001). Fetal ovaries were homogenized in $800 \mu \mathrm{L}$ of lysis buffer for 30 s (Ultraturrex T25, Ika Labotechnik, Germany), with the homogenate then split into two equal aliquots. Each aliquot was centrifuged at $12,000 \mathrm{~g}$ for $1 \mathrm{~min}$ through 2 DNA binding columns followed by centrifugation $(12,000 \mathrm{~g}$ for $1 \mathrm{~min})$ through an RNA-binding column. Prescribed washing steps were incorporated in accordance with the manufacturer's instructions, and an in-column DNase digest performed following the manufacturer's instructions. The RNA was eluted from each column by centrifugation $(10,000 \mathrm{~g}$ for $30 \mathrm{~s})$ with $55 \mu \mathrm{L}$ of DNase free water. To increase RNA recoveries, the eluate was reapplied to the column and the centrifugation was repeated. A further-off column DNase digest was performed using the Ambion DNA-free kit following the manufacturer's guidelines (Ambion). Samples were stored at $-70^{\circ} \mathrm{C}$.

RNA quantity and quality were measured using a Bioanalyser 2100 and the RNA 6000 pico kit (Agilent Technologies). Potential DNA contamination of RNA samples was determined using a Qubit assay (dsDNA BR, Thermo Fisher Scientific) following the manufacturer's instructions.

\section{mRNA enrichment}

ERCC control mixes (Ambion ERCC Spike-In Control Mixes, Cat 4456739. Thermo Fisher Scientific) were added to total RNA samples $(6 \mu \mathrm{L}$ of the supplied reagent at a 1:100 dilution in nuclease free water to $6 \mu \mathrm{g}$ of total RNA) prior to mRNA enrichment. The RNA aliquots (each containing $6 \mu \mathrm{g}$ of total RNA) were diluted to $150 \mu \mathrm{L}$ with nuclease free water and mRNA enrichment undertaken using the Dynabead mRNA Direct Micro kit (Life Technologies), following the manufacturer's instructions for samples containing 1-50 $\mu \mathrm{g}$ of total RNA.

\section{Library preparation}

Whole transcriptome libraries were constructed using the Ion Total RNAseq kit V2 (Thermo Fisher Scientific) as per the manufacturer's instructions for fragmented poly (A) RNA up to $5 \mu \mathrm{g}$. A $3 \mu \mathrm{g}$ aliquot of each mRNA enriched sample was used for library construction. Initial fragmentation using the supplied RNaselll was for $3 \mathrm{~min}$ at $37^{\circ} \mathrm{C}$. Library-specific barcodes were ligated to each library made from an individual ovary. Library quality and quantity was assessed using a Bioanalyser 2100 and the DNA 1000 pico kit (Agilent Technologies).

\section{Sequencing}

The emulsion PCR and enrichment process was performed using the Ion One Touch 2 System and the Ion PI Template OT2 200 Kit v3 (Thermo Fisher Scientific), following the manufacturer's instructions. Each emulsion PCR and sequencing process used a total of $100 \mu \mathrm{L}$ of pooled library (comprising a pool of between 3 and 12 barcoded libraries) at a final concentration of $10 \mathrm{pmol} / \mathrm{L}$ of CDNA. 
Ion Proton sequencing was performed using lon PI v2 chips. To control for technical variation, a total of 15 chips were sequenced, with each chip containing between 3 and 12 libraries. Each barcoded library was sequenced on 3-5 chips.

\section{Data processing}

The Fastx Tool Kit (v 0.0.14, http://hannonlab.cshl.edu/fastx_ toolkit/) was used to filter and trim low-quality sequences ( $>40 \%$ of bases with a Phred score $<25$ ), remove low-quality (Phred score $<25$ ) bases from the 3 ' end of sequencing reads and discard sequences shorter than 25 bases. Sequence quality was assessed using FastQC (v0.10.1).

Raw sequencing reads were mapped to a reference genome, Ovis Aries 3 (OAR3.1, GCF_000298735.1), (Archibald et al. 2010, Jiang et al. 2014) using STAR (v2.3.0.1) (Dobin et al. 2013). Data for each ERCC transcript (length and sequence) were incorporated into the sheep genome reference files. Sequencing files for each ovarian library were converted and merged to produce a single SAM file for each ovary using Samtools (v0.1.19-44428) (Li et al. 2009). Files were analyzed using Cufflinks (v2.2.1) (Trapnell et al. 2012) to generate expressed gene lists. Differential gene expression analysis was performed using Cuffdiff (v2.2) (Trapnell et al. 2012). The Benjamini-Hochberg procedure was applied to correct for multiple comparisons. A false discovery rate of $q<0.05$ was used as cut-off criteria to assign significance. Significant positive fold changes ranged from 1.4 to 58.3 and significant negative fold changes ranged from 1.1 to 20.0. At each gestational age, fragments per kilobase of exon per million reads mapped $(\mathrm{fpkm})$ values for ovaries from the restricted group are compared to the fpkm values for the maintenance group; thus, a positive fold-change indicates upregulation in the restricted group compared to the maintenance group, while a negative fold change indicates downregulation in the restricted group.

To determine potential biological pathways affected, and the functional significance of genes with significant differential expression (SDE) both Ingenuity Pathway Analysis (IPA, Qiagen) and Gene Ontology terms (GO terms) sourced from AMIGO (Carbon et al. 2009) were used. GO terms were analyzed for enriched terms using the Batch Genes tool and default settings in GOEAST (Zheng \& Wang 2008).

\section{Determination of the lower limit of detection (LLD) from ERCC control mixes}

The average measured fpkm value for each detected ERCC transcript was plotted against the known concentration of that transcript in the ERCC standard. Outliers were removed from the analysis until an $R^{2}$ value $>0.9$ was achieved. To achieve an $R^{2}$ value $>0.9$, all fpkm values $<0.1$ were removed. One additional transcript (ERCC0074) was also removed. ERCC0074 returned an average fpkm value of 1500, almost three-fold higher than any sample value in the dataset. The resulting linear relationship between known and measured concentrations indicated that the LLD for this dataset was 0.1 $\mathrm{fpkm}$. No fpkm values from the dataset were greater than the upper most remaining ERCC standard.

\section{Validation of fold changes using Nanostring}

The Nanostring nCounter XT gene expression assay (Nanostring Technologies, Seattle, WA, USA) was used to compare fold changes for a range of genes. The manufacturer's protocol was followed using $4 \mu \mathrm{L}$ of total RNA from the same extract used for RNAseq. Counts were normalized to housekeeping genes where RNAseq results showed consistent expression levels over both groups and both ages (YWHAZ, SDHA, GAPDH and G6PD) and analysis performed using the Nanostring $\mathrm{N}$ solver software (v2.6). Based on RNAseq gene expression data, genes with a range of fold-changes, a range of significance levels between groups, and a range of expression levels, were selected for Nanostring analysis. A total of 50 genes were selected that included the housekeeping genes. Code sets (reporter and capture probes) were synthesized by Nanostring Technologies (Nanostring Technologies).

\section{Results}

\section{Library and sequencing metrics}

Average RNA and library concentrations are presented in Table 1 for all 23 samples used for library construction. The average RIN value for RNA samples was 9.1 (range 8.8-9.8) and DNA contamination was below the detection limit of the assay employed $(10 \mathrm{ng} / \mu \mathrm{L})$. Library fragment lengths were $<200 \mathrm{bp}$.

Following sequencing, each library produced an average of 37.3 million reads, with an average read length of $84 \mathrm{bp}$, a GC content of $49 \%$, and a Phred score of 24. Following trimming and filtering, read length was reduced to $69 \mathrm{bp}$, and Phred score increased to 25 . The average per base mismatch rate over all libraries was $0.18 \%$. Seventy one percent of reads aligned to the sheep genome resulting in an average of 18.6 million aligned reads per library.

\section{Overall gene expression}

At day 55, 14,384 (maintenance) and 14,530 (restricted) annotated genes returned expression values greater than the LLD (0.1 fpkm), while 3406 (maintenance) and 3788 (restricted) unannotated genes returned expression values greater than the LLD. At day 75, 15,038 (maintenance) and 15,009 (restricted) annotated genes returned expression values greater than the LLD (0.1 fpkm), while 3567 (maintenance) and 3562 (restricted) unannotated genes returned expression values greater than the LLD.

\section{Differential gene expression}

Complete lists of SDE genes at days 55 and 75 are available in Supplementary data 1 (see section on supplementary data given at the end of this article). The numbers of SDE genes are given as metrics in Table 2 and as volcano plots in Fig. 1. While at day 75 over 
Table 1 RNA recoveries and cDNA library concentrations.

\begin{tabular}{lcccc}
\hline & Day $\mathbf{5 5}$ maintenance & Day 55 restricted & Day 75 maintenance & Day $\mathbf{7 5}$ restricted \\
\hline Ovary weight $(\mathrm{mg})$ & $10.3 \pm 0.9$ & $10.1 \pm 0.7$ & $23.9 \pm 1.3$ & $24.9 \pm 1.3$ \\
RNA concentration $(\mathrm{ng} / \mu \mathrm{L})$ & $104.5 \pm 13.5$ & $135.4 \pm 18.7$ & $332 \pm 14.8$ & $302.1 \pm 35.9$ \\
Library concentration $(\mathrm{ng} / \mu \mathrm{L})$ & $13.8 \pm 1.9$ & $13.5 \pm 2.0$ & $14.5 \pm 2.4$ & $18.3 \pm 1.9$ \\
Library molarity $(\mathrm{nmol} / \mathrm{L})$ & $130.0 \pm 18.8$ & $135.1 \pm 17.1$ & $119.2 \pm 17.9$ & $165.3 \pm 12.0$ \\
\hline
\end{tabular}

twice as many genes were differentially expressed, the fold changes were considerably less than those observed at day 55. The average negative fold change at day 75 was -2.0 (this excludes CCL16, this gene, involved in immunoregulatory and inflammatory responses, was expressed in maintenance ovaries but no expression was evident in restricted ovaries), while at day 55 this was -9.0. The average positive fold change at day 75 was 1.8 while at day 55 this was 5.0.

The ten most SDE genes (by both positive and negative fold change) are presented in Table 3 (day 55) and Table 4 (day 75). Cell-specific expression patterns of these genes within the fetal ovary have been sourced from a number of studies over a variety of mammalian species. These studies were selected so that the developmental timing was similar to the current study (Choi et al. 2007, Fowler et al. 2009, Regassa et al. 2011, Zhang et al. 2011, Jameson et al. 2012, Bellingham et al. 2013, Bonnet et al. 2013, Li et al. 2013, Bebbere et al. 2014, Soh et al. 2015). GO annotations were sourced from (Carbon et al. 2009). Of the 55 known SDE genes identified at day 55 , the cell-specific expression pattern of 35 genes has been published. Of these 35 genes, 16 are expressed preferentially or exclusively in germ cells. Four of these genes, while their expression pattern in fetal ovaries is unknown, are reported to be expressed specifically in adult oocytes, a further13 are expressed in all ovarian cell types including germ cells, and two have been shown not to be expressed in germ cells. Of the 122 SDE genes at day 75, 25 are known to be specifically or preferentially expressed in germ cells, 11 while their expression pattern in fetal ovaries is unknown, are known to be specifically or preferentially expressed in adult oocytes, 13 are known to either not be expressed in germ cells or have low expression in germ cells and 34 are known to be expressed in all cells of the fetal ovary including germ cells. The cell-specific expression of 39 genes is unknown.

Of the most upregulated genes in restricted ovaries at day 55 , the GO annotations can largely be assigned to two categories: nucleic acid binding and ion transport (Table 3). Genes downregulated in restricted ovaries can be assigned to only two GO categories: carrier proteins of the albumin family and those with protease inhibitor activity. While GO annotations for VTN do not include protease inhibitor activity, VTN is known to bind to several protease inhibitors (Deng et al. 1996) and has been shown to play a role in proteolytic cascades (Preissner et al. 1997). While less clear cut, this pattern of GO annotations remains present for the most SDE genes at day 75 (Table 4).

Affected pathways presented are based on the $P$ value generated by IPA, indicating that the expression of a significant number of genes within that pathway was affected by the nutritional regime. While $z$ scores are used by IPA to indicate activation or inhibition or pathways, in this dataset $z$ scores could not be calculated for most of the affected pathways. Of the 15 pathways presented at day 55 (Table 5), z scores were calculated for only two pathways, there was insufficient data ( $<$ four target genes affected) for three pathways, while the remaining ten pathways were ineligible for activity analysis due to insufficient information in the literature of QIAGEN Knowledge Base. At day 75, of the 21 pathways presented (Table 6), z scores were generated for three pathways, there was insufficient data for four pathways and the remaining 14 pathways were ineligible for activity analysis. The top canonical pathways identified by IPA as affected at day 55 (Table 5) included LXR/RXR activation, FXR/RXR activation, acute phase response signaling, protein citrullination, citrulline-nitric oxide cycle, nNOS signaling in skeletal muscle, super pathway of citrulline metabolism and calcium transport 1 . Of these, LXR/RXR activation was predicted as downregulated while for the remainder low activation scores (based on the expression levels/ patterns of key focus genes within a pathway) meant activity patterns were not able to be predicted. At day 75 , canonical pathways affected (Table 6) included acute phase response signaling, nitric oxide signaling in skeletal muscle, LXR/RXR activation, FXR/RXR activation, production of nitric oxide and reactive oxygen species in macrophages, vitamin C transport, ascorbate recycling, glutathione redox reactions, citrulline-nitric oxide cycle and protein citrullination. Of these, LXR/ RXR activation, and production of nitric oxide (NO) and reactive oxygen species (ROS) in macrophages were

Table 2 Summary of differential gene expression between fetal ovaries whose dams were exposed to either maintenance or restricted nutrition.

\begin{tabular}{lcc}
\hline Differentially expressed sequences & Day $\mathbf{5 5}$ & Day $\mathbf{7 5}$ \\
\hline Total & 69 & 145 \\
Unassigned to a gene identifier & 14 & 23 \\
Known genes common to both ages & 16 & \\
Known genes unique to each age & 39 & 106 \\
\% Upregulated in restricted group & 51 & 66 \\
\hline
\end{tabular}



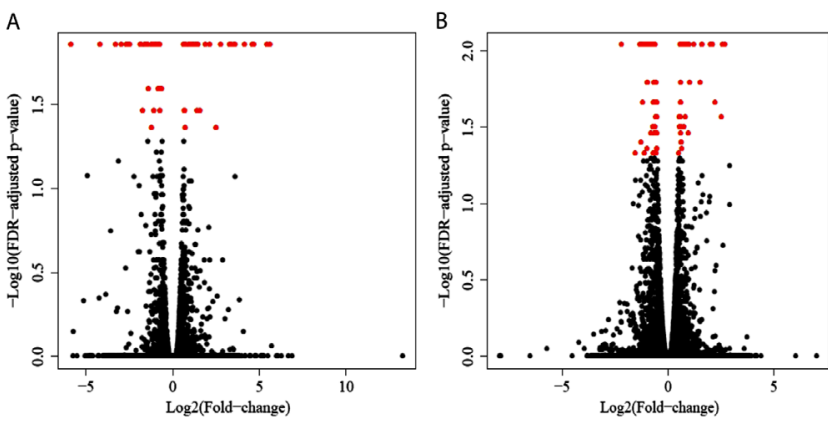

Figure 1 Volcano plots illustrating fold change vs false discovery rate. (A) Day 55 genes and (B) day 75 genes. Differentially expressed genes (between nutritional groups) are represented by red dots. Genes not differentially expressed are represented by black dots.

predicted as downregulated while for the remainder the activity pattern could not be predicted.

\section{Validation of changes using Nanostring}

Of the 46 genes analyzed by Nanostring, 18 returned at least one sample which was below the detection limit of the Nanostring nCounter XT gene expression assay. These genes were removed from the comparative analysis. The remaining data are presented as a BlandAltman plot (Fig. 2) comparing Nanostring and RNAseq fold changes. An $R^{2}$ value of 0.92 indicates a strong, consistent proportional error situation. That is, the larger the fold change then the larger the difference between the two techniques, where the fold change detected by Nanostring is larger than that detected by RNAseq.
However, in the context of this study, the high $R^{2}$ value demonstrates a consistency between the techniques and that Nanostring data support the scale and direction of the fold changes obtained using RNAseq. Fold changes for RNAseq and Nanostring for each gene at each age are presented in Supplementary data 2.

\section{Discussion}

The companion paper (ref companion paper) reported increased indicators of fertility in female offspring from dams exposed to an initial restricted plane of nutrition. Further, while no differences were observed in the pattern of fetal germ cell development at the cessation of the nutrition restriction period (day 55), Twenty days following the change to ad libitum feeding, fetal ovaries from offspring of dams exposed to restricted nutrition contained more germ cells but a lower proliferation rate was apparent. While the area staining positive for autophagy (MAPLC3B) was not different between nutritional groups, the intensity of this staining was higher in day 75 fetal ovaries from dams exposed to restricted nutrition. No differences were apparent between nutrition groups in the levels of germ cell apoptosis at both day 55 and 75 of gestation (as determined by TUNEL staining). The appearance of most changes in morphological aspects of germ cell development only after the transition from a restricted plane of nutrition to ad libitum nutrition suggests that it is the change in diet which may be important in establishing the observed effects. The objective of the current study was to examine fetal ovaries, from the same cohort of animals,

Table 3 Most differentially regulated genes (by fold change) at day 55 of gestation.

\begin{tabular}{|c|c|c|c|c|}
\hline Gene & Reported expression & Maintenance fpkm & Restricted fpkm & GO annotation(s) \\
\hline ZP3 & Germ cell & $0.1 \pm 0.03$ & $7.3 \pm 7.0$ & lon transport \\
\hline FOXR1 & Germ cell & $0.3 \pm 0.04$ & $5.5 \pm 5.0$ & Transcription factor, nucleic acid binding \\
\hline FIGLA & Germ cell & $0.8 \pm 0.3$ & $8.2 \pm 7.4$ & Transcription factor, nucleic acid binding \\
\hline PADI6 & Germ cell & $2.5 \pm 0.2$ & $15.9 \pm 13.0$ & lon transport \\
\hline KIAA1324L & Unknown & $0.5 \pm 0.1$ & $2.8 \pm 2.3$ & Ion transport \\
\hline $\mathrm{HIST} 2 \mathrm{H} 2 \mathrm{BF}$ & Unknown & $5.3 \pm 1.2$ & $29.9 \pm 23.0$ & DNA binding \\
\hline GDF9 & Germ cell & $2.5 \pm 3.2$ & $9.4 \pm 6.7$ & Cytokine activity \\
\hline NOS $1^{*}$ & Germ cell & $0.5 \pm 0.01$ & $1.7 \pm 0.9$ & Ion transport, protein binding \\
\hline PNLDC1 & Germ cell & $2.5 \pm 0.5$ & $7.8 \pm 6.1$ & Nucleic acid binding \\
\hline SAMD15 & Unknown & $2.4 \pm 0.6$ & $6.9 \pm 4.7$ & Unknown function \\
\hline$A F P$ & Unknown & $30.0 \pm 19.5$ & $0.6 \pm 0.2$ & Carrier protein albumin family \\
\hline FETUB & Germ cell & $10.7 \pm 6.4$ & $0.3 \pm 0.1$ & Protease inhibitor \\
\hline SERPINA1 & Unknown & $84.8 \pm 50.2$ & $3.3 \pm 1.3$ & Protease inhibitor \\
\hline$A M B P$ & Unknown & $7.2 \pm 4.0$ & $0.3 \pm 0.1$ & Protease inhibitor vesicle development \\
\hline GC & All & $5.3 \pm 3.7$ & $0.2 \pm 0.1$ & Carrier protein albumin family \\
\hline AHSG & Unknown & $184.8 \pm 105.2$ & $10.5 \pm 8.3$ & Protease inhibitor vesicle development \\
\hline$A L B$ & Germ cell & $16.1 \pm 9.5$ & $1.3 \pm 0.2$ & Carrier protein albumin family \\
\hline$V T N$ & Not germ cell & $5.6 \pm 3.7$ & $0.5 \pm 0.4$ & Binds to protease inhibitors \\
\hline SPP2 & Unknown & $6.4 \pm 4.0$ & $0.6 \pm 0.3$ & Protease inhibitor \\
\hline ITIH2 & Unknown & $2.2 \pm 1.4$ & $0.2 \pm 0.2$ & Protease inhibitor \\
\hline
\end{tabular}

Positive fold change indicates upregulation in restricted ovaries. Expression patterns are sourced from (Choi et al. 2007, Fowler et al. 2009, Regassa et al. 2011, Zhang et al. 2011, Jameson et al. 2012, Bellingham et al. 2013, Bonnet et al. 2013, Li et al. 2013, Bebbere et al. 2014, Soh et al. 2015).

*Indicates adjusted $P$ value $<0.05$, all other $q$ values $<0.01$. 
Table 4 Most differentially regulated genes (by fold change) at day 75 of gestation.

\begin{tabular}{|c|c|c|c|c|}
\hline Gene & Expression & Maintenance fpkm & Restricted fpkm & GO annotation(s) \\
\hline SLC12A3* & Oocyte (adult) & $1.2 \pm 0.2$ & $3.4 \pm 1.3$ & Ion transport \\
\hline ADAMTS14 & Oocyte (adult) & $5.3 \pm 0.7$ & $13.4 \pm 3.4$ & Peptidase activity \\
\hline TDRD10 & Germ cell & $21.8 \pm 1.3$ & $49.9 \pm 11.6$ & Nucleic acid binding \\
\hline MATER & Germ cell & $3.1 \pm 0.5$ & $7.1 \pm 2.2$ & Germ cell development \\
\hline RBM2O & Unknown & $1.7 \pm 0.1$ & $3.8 \pm 0.4$ & Nucleic acid binding \\
\hline CHL1 & Oocyte (adult) & $9.7 \pm 2.1$ & $21.8 \pm 8.4$ & Protease binding \\
\hline SPTBN5 & Unknown & $1.1 \pm 0.1$ & $2.4 \pm 0.5$ & Actin binding \\
\hline NLRC5 & All cells & $2.2 \pm 1.0$ & $4.7 \pm 1.0$ & DNA binding \\
\hline TSKS* & Germ cell & $4.3 \pm 0.7$ & $9.4 \pm 1.2$ & Protein kinase binding \\
\hline RYR3 & Unknown & $0.9 \pm 0.1$ & $2.0 \pm 0.4$ & Ion transport \\
\hline CCL16\# & Unknown & $2.3 \pm 1.0$ & $0.0 \pm 0.0$ & Chemokine activity \\
\hline$A M B P$ & Unknown & $9.0 \pm 2.2$ & $1.3 \pm 1.2$ & Protease inhibitor \\
\hline AHSG & Unknown & $108.9 \pm 28.2$ & $18.3 \pm 15.9$ & Protease inhibitor \\
\hline$P L G$ & Unknown & $1.8 \pm 0.5$ & $0.4 \pm 0.2$ & Protease inhibitor \\
\hline SERPINA1 & Oocyte (adult) & $57.4 \pm 17.1$ & $13.4 \pm 0.5$ & Protease inhibitor \\
\hline$A F P$ & Unknown & $12.5 \pm 4.6$ & $2.9 \pm 2.7$ & Carrier protein albumin family \\
\hline$A L B$ & Unknown & $16.3 \pm 4.7$ & $4.1 \pm 3.0$ & Carrier protein albumin family \\
\hline$A P C D D 1 L$ & Unknown & $21.2 \pm 5.9$ & $7.1 \pm 1.2$ & Membrane component \\
\hline MOXD1 & Unknown & $15.7 \pm 2.5$ & $6.7 \pm 0.8$ & Ion transport \\
\hline CALB2 & Unknown & $18.3 \pm 3.9$ & $9.0 \pm 1.6$ & Ca transport \\
\hline
\end{tabular}

Positive fold change indicates upregulation in restricted ovaries. Cell-specific expression pattern GO annotations are sourced as described for Table 3.

\#Represents expression in maintenance ovaries and no expression in restricted ovaries. *Indicates adjusted $P$ value $<0.05$, all other $q$ values $<0.01$.

using RNAseq, to identify genes and potential pathways affected by differences in maternal plane of nutrition.

At day 55 (the cessation of nutrition restriction), 69 genes were differentially expressed while at day 75 (nutrition restriction followed by 20 days ad libitum feeding), 145 genes were differentially expressed. The number of differentially expressed genes are consistent with the findings of both Costa et al. (2014) and Lea et al. (2016). Subsequent analysis identified a number of pathways and GO terms linking many of these differentially expressed genes. The potential for differential expression to affect germ cell development is highlighted when examining the most affected genes by fold change at each age. Of those genes with a known cell-specific expression pattern, $9 / 11$ at day 55 and $3 / 7$ at day 75 are expressed either exclusively or preferentially in germ cells, the remainder is expressed in all cell types or their expression pattern in the fetal ovary is unknown.

The focus of this discussion is exploring how the affected genes, pathways and GO terms may contribute

Table 5 Day 55 most affected canonical pathways identified by IPA.

\begin{tabular}{|c|c|c|}
\hline Ingenuity canonical pathways & $P$ value & Molecules \\
\hline Acute phase response signaling** & $1.23 \mathrm{E}-08$ & $\begin{array}{l}\mathrm{AGT} \downarrow, \mathrm{APOA} 2 \downarrow, \mathrm{FGB} \downarrow, \mathrm{APOH} \downarrow, \mathrm{SERPINA} 1 \downarrow, \mathrm{AHSG} \downarrow, \\
\mathrm{AMBP} \downarrow, \mathrm{ITIH} 2 \downarrow, \mathrm{ALB} \downarrow\end{array}$ \\
\hline LXR/RXR activation** & $1.55 \mathrm{E}-08$ & $\begin{array}{l}\text { AGT } \downarrow, V T N \downarrow, \text { APOA } 2 \downarrow, \text { APOH } \downarrow, \text { SERPINA } 1 \downarrow, \text { AHSG } \downarrow, \\
\text { AMBP } \downarrow, \mathrm{ALB} \downarrow\end{array}$ \\
\hline FXR/RXR activation & $2.14 \mathrm{E}-08$ & $\begin{array}{l}\mathrm{AGT} \downarrow, \mathrm{VTN} \downarrow, \mathrm{APOA} 2 \downarrow, \mathrm{APOH} \downarrow, \mathrm{SERPINA} 1 \downarrow, \mathrm{AHSG} \downarrow, \\
\mathrm{AMBP} \downarrow, \mathrm{ALB} \downarrow\end{array}$ \\
\hline Embryonic stem cell differentiation into cardiac lineages & 5.89E-04 & NANOG $\downarrow$, POU5F1 $\downarrow$ \\
\hline Transcriptional regulatory network in embryonic stem cells & 9.55E-03 & NANOG $\downarrow$, POU5F1 $\downarrow$ \\
\hline $\begin{array}{l}\text { Role of Oct4 in mammalian embryonic stem cell } \\
\text { pluripotency* }\end{array}$ & $1.26 \mathrm{E}-02$ & NANOG $\downarrow$, POU5F1 $\downarrow$ \\
\hline Myo-inositol biosynthesis & 1.48E-02 & IMPAD1 $\downarrow$ \\
\hline Protein citrullination & $1.82 \mathrm{E}-02$ & PADI6 $\uparrow$ \\
\hline Citrulline-nitric oxide cycle & $1.82 \mathrm{E}-02$ & NOS1 1 \\
\hline NRF2-mediated oxidative stress response* & $2.88 \mathrm{E}-02$ & $\mathrm{ACTB} \uparrow, \mathrm{GSTM} 3 \uparrow, \mathrm{DNAJB} 14 \downarrow$ \\
\hline Production of nitric oxide and ROS in macrophages* & 2.88E-02 & APOA $2 \downarrow$, SERPINA $1 \downarrow$, ALB $\downarrow$ \\
\hline Calcium transport I & $3.63 \mathrm{E}-02$ & ATP2C $2 \downarrow$ \\
\hline Mouse embryonic stem cell pluripotency & 4.79E-02 & NANOG $\downarrow$, POU5F1 $\downarrow$ \\
\hline Super pathway of citrulline metabolism & $5.01 \mathrm{E}-02$ & NOS1 $1 \uparrow$ \\
\hline
\end{tabular}

Arrows indicate up or down-regulation in restricted fetal ovaries. All remaining pathways were not eligible for predictions of activation or inhibition because there is not enough information in the literature of Qiagen Knowledge Base at this time about how expression patterns of molecules affect their activity.

*Indicates there is not enough evidence from the dataset to make a prediction of activity; ${ }^{* *} z$ score calculated at -2.8 for LXR/RXR activation and zero for acute phase response signaling. 
Table 6 Day 75 most affected canonical pathways identified by IPA.

\begin{tabular}{|c|c|c|}
\hline Ingenuity canonical pathways & $P$ value & Molecules \\
\hline Acute phase response signaling** & 2.69E-03 & SERPINA $1 \downarrow$, AHSG $\downarrow$, AMBP $\downarrow$, PLG $\downarrow$, ALB $\downarrow$ \\
\hline $\mathrm{nNOS}$ signaling in skeletal muscle cells & $3.16 \mathrm{E}-03$ & $\mathrm{RYR} 3 \uparrow, \mathrm{NOS} 1 \uparrow$ \\
\hline Vitamin C transport & $3.16 \mathrm{E}-03$ & $\mathrm{GLRX} \uparrow, \mathrm{SLC} 2 \mathrm{~A} 1 \downarrow$ \\
\hline Production of nitric oxide and ROS in macrophages** & $3.47 \mathrm{E}-03$ & 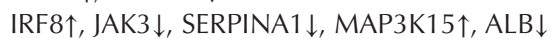 \\
\hline LXR/RXR activation** & 4.79E-03 & SERPINA $1 \downarrow, A H S G \downarrow, A M B P \downarrow, A L B \downarrow$ \\
\hline FXR/RXR activation & $5.62 \mathrm{E}-03$ & SERPINA1 $\downarrow, A H S G \downarrow, A M B P \downarrow, A L B \downarrow$ \\
\hline Cardiolipin biosynthesis II & $1.12 \mathrm{E}-02$ & PGS1 $\downarrow$ \\
\hline Inhibition of angiogenesis by TSP $1 *$ & $1.55 \mathrm{E}-02$ & HSPG $2 \downarrow$, GUCY1A3 $\uparrow$ \\
\hline Coagulation system* & $1.66 \mathrm{E}-02$ & SERPINA $1 \downarrow$, PLG $\downarrow$ \\
\hline Biotin-carboxyl carrier protein assembly & $1.66 \mathrm{E}-02$ & $\mathrm{ACACB} \uparrow$ \\
\hline Tyrosine biosynthesis IV & $1.66 \mathrm{E}-02$ & PCBD1 $\uparrow$ \\
\hline Ascorbate recycling (cytosolic) & $2.24 \mathrm{E}-02$ & $\operatorname{GLRX\uparrow }$ \\
\hline Glutathione redox reactions II & $2.24 \mathrm{E}-02$ & GLRX $\uparrow$ \\
\hline Phenylalanine degradation I (aerobic) & $2.24 \mathrm{E}-02$ & PCBD1 1 \\
\hline Corticotropin releasing hormone signaling & $2.45 \mathrm{E}-02$ & 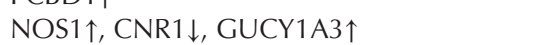 \\
\hline Protein citrullination & $2.75 \mathrm{E}-02$ & PADI6 $\uparrow$ \\
\hline Citrulline-nitric oxide cycle & $2.75 \mathrm{E}-02$ & NOS1 $\uparrow$ \\
\hline Pentose phosphate pathway (non-oxidative branch) & $3.31 \mathrm{E}-02$ & TKT $\downarrow$ \\
\hline IL-12 signaling and production in macrophages & $3.89 \mathrm{E}-02$ & IRF8 $\uparrow$, SERPINA $1 \downarrow$, ALB $\downarrow$ \\
\hline Synaptic long term depression* & 4.57E-02 & 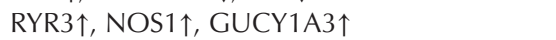 \\
\hline Antiproliferative role of somatostatin receptor $2^{*}$ & 4.90E-02 & 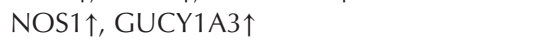 \\
\hline
\end{tabular}

Arrows indicate up or down-regulation in restricted fetal ovaries. All remaining pathways were not eligible for predictions of activation or inhibition because there is not enough information in the literature of QIAGEN Knowledge Base at this time about how expression patterns of molecules affect their activity.

*Indicates there is not enough evidence from the dataset to make a prediction of activity. ${ }^{* *} z$ score calculated at -2.0 for LXR/RXR Activation, 0.45 for production of nitric oxide and ROS in macrophages and zero for acute phase response signaling.

to the phenotypic effects observed in both the day 75 fetal ovaries, and the female offspring from this cohort of animals reported in the companion paper.

The oocyte-specific transcription factor FIGLA showed a ten-fold upregulation at day $55(q=0.01)$ and a two-fold upregulation at day $75(q=0.02)$. FIGLA is known to regulate expression of the zona pellucida (ZP) genes (Joshi et al. 2007). Of the ZP genes, there was a 58 fold upregulation of $Z P 3$ at day $55(q<0.01)$, while large fold changes were observed for both $Z P 2$ and $Z P 4$ at this age, these were not significant due to large variation between individual ovaries ( $q=0.3$ and 0.9 respectively). Electron microscope examination of sheep fetal ovaries at day 55 of gestation did not reveal indications of ZP formation (Sawyer et al. 2002). Similarly, expression of ZP3 has also been observed in human ovaries prior to follicle formation (Törmälä et al. 2008). Thus, it appears likely that at this stage of development, ZP3 is playing some alternative role in germ cell development rather than zona pellucida formation. GO annotations for ZP3 include both signal transducer activity and $\mathrm{Ca}^{2+}$ channel activity.

The role of $Z P 3$ in $\mathrm{Ca}^{2+}$ channel activity is of particular interest as IPA identified ion transport as a pathway affected by nutritional restriction. Further, at least three other upregulated germ cell specific/ preferential genes have GO annotations relating to ion transport and binding: NOS1 (3.4 fold at day 55, $q=0.03 ; 2$ fold at day 75, $q=0.01$ ), PADI6 (6.4 fold at day $55, q=0.01 ; 2.1$ fold at day $75, q=0.01$ ) and
KIAA1324L (6 fold at day 55, $q=0.01$ ). $\mathrm{Ca}^{2+}$ is known to play key roles in other affected pathways particularly citrullination and nitric oxide production by NOS1 (Clementi 1998). Conversion of arginine to nitric oxide and citrulline by NOS1 is a $\mathrm{Ca}^{2+}$-dependent reaction (Wendehenne et al. 2001), this reaction is also catalyzed by $\mathrm{Ca}^{2+}$ dependent peptidylarginine deaminases including PADI6 (Mohamed et al. 2012). NOS1 and PADI6 are upregulated in fetal ovaries from dams exposed to restricted nutrition at both day 55 (3.4-fold and 6.4-fold respectively) and day 75 (2-fold and 2.1-fold respectively).

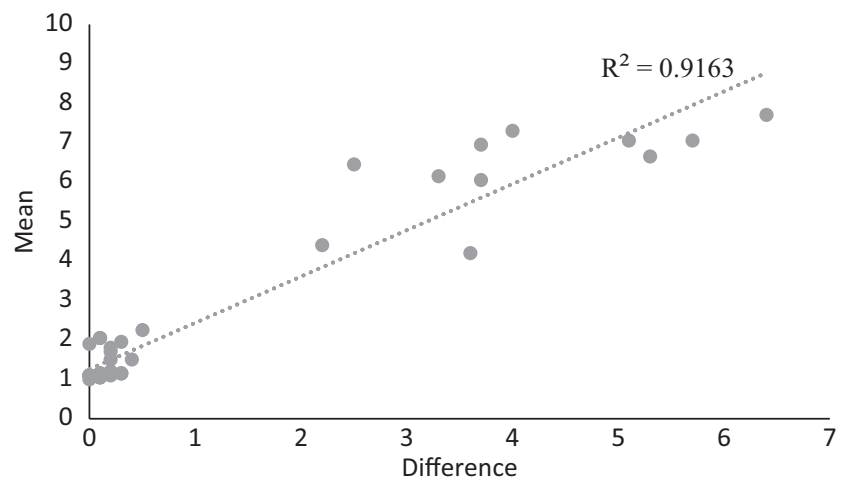

Figure 2 Bland-Altman plot comparing fold changes obtained from Nanostring and RNAseq for 28 genes. Vertical axis represent mean fold change of the two techniques, horizontal axis represents the difference in fold change obtained from the two methodologies. 
NO is known to play a role in DNA damage and repair although its precise role is complex with NO-induced DNA damage occurring through a variety of cell-specific and/or dose-dependent mechanisms as described by Tamir et al. (1996). However, it is primarily not NO per se, which causes DNA damage, but the products (such as $\mathrm{N}_{2} \mathrm{O}_{3}$ and $\mathrm{ONOO}$ ) of the reaction between $\mathrm{NO}$ and $\mathrm{ROS}$ (Burney et al. 1999). As NOS1 and PADI6 are involved in NO production, are preferentially expressed in germ cells and are upregulated in nutritionally restricted fetal ovaries at a time of significant germ cell proliferation, apoptosis and meiosis, it seems logical to hypothesize that this upregulation may have a negative effect on the DNA status in these cells. Supporting this contention, Murdoch et al. demonstrated in sheep, increased oxidative base lesions in DNA of day 78 fetal oogonia exposed to restricted nutrition from day 28 of gestation (Murdoch et al. 2003). While Murdoch did not examine the mechanism by which the increased lesions arise, we hypothesize that in a restricted maternal nutritional environment NO may be a contributing factor.

The improved indicators of fertility in the offspring from this cohort of animals described in the companion study would suggest however beneficial effects on germ cell development. The companion study also highlighted the potential importance of the change in diet from restricted to ad libitum. In the current study, at day 75 following the change to ad libitum feeding, IPA identified three affected pathways -glutathione REDOX reactions, vitamin $\mathrm{C}$ transport and ascorbate recycling, which may have beneficial effects by blocking NO-induced DNA damage during the crucial period where meiosis is prevalent (day 55-75).

One of the major functions of the glutathione REDOX pathway is to regulate the intracellular levels of ROS (Mailloux et al. 2013). Vitamin C (ascorbate) is one compound that can potentiate NO synthesis (Heller et al. 2001) and is also a known antioxidant. Treatment with vitamin $\mathrm{C}$ has been shown to inhibit ROS generation and afford protection to spermatozoa in rats (Hsu et al. 1998), and the potential for vitamin C to afford some protection from DNA damage particularly in an under-nourished situation has been reported previously (Sram et al. 2012). Additionally, Zhang reported that fetal germ cells from mice deficient in NOS3, and exposed to the environmental estrogen bisphenol A, showed an increase in chromosomal errors during meiosis (Zhang 2007), suggesting a protective effect of $\mathrm{NO}$ in fetal germ cells. Thus, these three affected pathways have the potential to limit NO-induced DNA damage and promote the beneficial effects of $\mathrm{NO}$ on cell survival, proliferation and apoptosis as described by Napoli et al. (2013). Potentially further contributing to an improved germ cell DNA status at day 75 are two upregulated genes involved in DNA repair, LIG1 (1.5 fold, $q=0.03$ ) and PARP2 (1.5 fold, $q=0.03$ ). Potentially further supporting this concept is the finding at day 75 of expression of CCL16 in maintenance ovaries while in restricted ovaries there was no detectable expression of CCL16. Expression of CCL16 has been shown to increase in response to oxidative stress (Shini \& Kaiser 2009), thus, the lack of expression in restricted ovaries at day 75 is consistent with the concept of lower oxidative DNA damage in these ovaries at day 75 .

The role of $\mathrm{NO}$ in ovarian development is complex as $\mathrm{NO}$ is involved in numerous cell and developmental processes. Additionally, NOS is present in three distinct isoforms (Wendehenne et al. 2001). The potential importance of the NOS and citrullination pathways in fetal development has been highlighted by $\mathrm{Wu}$ et al. (2004) although largely in the context of placental development and/or angiogenesis. In sheep, allantoic fluid concentrations of citrulline increase 18-fold between days 30 and 60 (Kwon et al. 2003). Maternal nutritional restriction decreases fetal plasma arginine concentrations in the pig at day 60 of gestation (Wu et al. 1998). Restricted maternal nutrition in sheep between days 28 and 78 of gestation decreases maternal and fetal plasma levels of both arginine and citrulline (Kwon et al. 2004). A study using NOS3deficient mice showed a relationship between impaired NO production and intra-uterine growth retardation (Hefler et al. 2001), a relationship that can be reversed by arginine supplementation (Vosatka et al. 1998). While there is no evidence to suggest that fetal ovarian NOS1 (or PADI6) contribute to these observations, it does however highlight the potential significance of the arginine-citrulline-NO pathways in fetal development and provides some evidence that these pathways can be influenced by maternal nutrition.

$\mathrm{NO}$ is also known to play an important role in angiogenesis, although this function is normally attributed to NOS3 (Cooke 2003), which in the fetal ovary is predominantly expressed in endothelial cells (Jameson et al. 2012) and not differentially expressed between nutritional groups. AS NOS1 and PADI6 expression is localized to either germ cells or pregranulosa cells, it seems unlikely that the differences in NOS1 and PADI6 expression would have a significant effect on angiogenesis.

The discussion of potentially elevated levels of germ cell NO (via NOS1) may seem at odds with the predicted downregulation of the production of $\mathrm{NO}$ and ROS in macrophages pathway at day 75 . However, the inducible form of NOS (NOS2) is responsible for $\mathrm{NO}$ production in macrophages (Fang \& Vazquez-Torres 2002) and NOS2 is subject to different regulatory mechanisms than NOS1 (Nanetti et al. 2004, Pautz et al. 2010).

While the upregulation of germ cell-specific genes is a notable pattern in this data set, downregulated genes observed are also likely to play an important role. The fold changes, particularly at day 55, in these genes are greater than those observed in most upregulated genes. Specifically, expression of genes for carrier proteins of 
the albumin family $A L B, A F P$ and $C C$ all show large negative fold changes $(-48,-12$, and -24 respectively, $q<0.01$ in all cases). These genes are primarily expressed in liver and bind to a number of compounds including steroids and cations such as $\mathrm{Ca}^{2+}$ in plasma (Noël et al. 2010). The expression pattern and role of the members of the albumin family in the fetal ovary are yet to be fully investigated. It is therefore difficult to translate the differences in gene expression to the changes observed in the fetal ovary. While serum levels of albumin are known to affect levels of intracellular factors such as $\mathrm{Ca} 2+$ (Fuentes et al. 1997), the potential contribution of intracellular albumin in cell homeostasis has also been raised previously (Krishna \& Spanel-Borowski 1989). Downregulation of these genes may serve to increase the availability of the unbound compounds for cellular functions, conceivably an important concept given the important roles of steroids in gonadogenesis (Kezele \& Skinner 2003) and $\mathrm{Ca}^{2+}$ as discussed previously.

AFP is considered the fetal equivalent of albumin. Expression of $A F P$ in the fetus declines with gestational age as expression of $A L B$ increases, and by birth, liver expression of AFP is negligible (Gabant et al. 2002). Despite its abundance early in fetal life, AFP is not essential for development (Gabant et al. 2002). However, $A F P$ is required for female fertility as $A F P$-null mice develop to adulthood, but are infertile (Gabant et al. 2002). This infertility is thought to be due to effects on the hypothalamic-pituitary system where the estrogenbinding properties of AFP have a neuroprotective effect on the fetal brain (De Mees et al. 2006). At day 55 of gestation, the hypothalamic-pituitary system is yet to develop in sheep (Thomas et al. 1993), and therefore, it seems unlikely that the differences in AFP expression at this age are producing an effect at the hypothalamus or pituitary. However, expression of AFP has been observed in ovarian follicles of pregnant rats and the level of expression appears related to the health of the follicle, suggesting some link between this gene and ovarian function (Seralini et al. 1986). While potential effects of these differentially expressed albumin family members on ovarian development and subsequent fertility are apparent, further work is required to establish if this differential expression contributes to the phenotypes observed in both fetal ovaries and adult fertility from this cohort of animals.

$A F P, A L B$ and GC are also members of the HDL/ LDL family. Similarly other genes downregulated in this dataset are also classified as members of the HDL/LDL family. FETUB, SERPINA1, SERPINA5, AMBP, AHSG, $I T I H 2, A P O H, A G T, H P X$ and $V T N$ are all downregulated at day 55 with fold changes ranging from -43 to -3 , and $q$ values ranging from $<0.01$ to 0.04 . SERPINA1, $A M B P, A H S G$ and VTN are also downregulated at day 75 with fold changes ranging from -5.8 to -3.2 and $q$ values ranging from $<0.01$ to 0.05 . Downregulation of the HDL family members (AGT, VTN, APOA2, APOH,
SERPINA1, AHSG, AMBP and ALB) is responsible for the predicted effects on the LXR/RXR and FXR/RXR pathways at both day 55 and 75 of gestation. These nuclear receptors serve to regulate multiple metabolic pathways, particularly cholesterol metabolism in response to extracellular signals (Kalaany \& Mangelsdorf 2006). Effects on these pathways may indicate changes in cholesterol/steroid metabolism. However, levels of steroid gene expression were similar between groups at both gestational ages and no differences in steroid concentrations in fetal plasma at day 75 were observed in this cohort of animals (ref companion paper). Thus, there is no evidence from this study to suggest that the differences in germ cell development and the phenotypic differences in fertility indicators observed in the female offspring result from differences in steroid production in the developing ovaries.

While differences in HDL/LDL gene expression levels at both gestational ages do not appear to affect steroid production, it is of interest that many of the downregulated HDL/LDL family members also show protease inhibitor activity. These include FETUB, SERPINA1, SERPINA5, $A M B P, A H S G, S P P 2$, and ITIH at day 55, and AMBP, AHSG, PLG and SERPINA1 at day 75. The actions of protease inhibitors can either be destructive (destroying protein function) or positive (activation of a function or pathway) (Law et al. 2006). Protease inhibitors control a wide range of biological processes including proliferation (March et al. 1993), apoptosis (Mongia et al. 2004) and autophagy (Gibellini et al. 2012) and inflammation (Safavi \& Rostami 2012). Thus, potential for differential expression of protease inhibitors to have impacts on ovarian development is profound. The role of protease inhibitors in fetal ovaries is unclear, and the cell-specific expression pattern for the SDE protease inhibitors has not been published for fetal ovaries. It is also unclear whether the SDE protease inhibitors reported in the current study are able to interact with those proteases involved in germ cell development and thereby influence the establishment of the ovarian reserve, this hypothesis requires further study.

Within the fetal or immature mammalian ovary, the process of autophagy has been implicated in both germ cell death (Escobar et al. 2008, Rodrigues et al. 2009) and germ cell survival (Gawriluk et al. 2011). Tsujimoto proposes that upregulation of the autophagy associated genes ATG5 and ATG6, compared to other ATG genes, indicates that autophagy is playing a role in cell death as opposed to cell survival (Tsujimoto \& Shimizu 2000). In the current study, the expression of both ATG5 and ATG6 is comparable to other ATG genes (Supplementary data 1). This suggests that at day 55 and 75 in the sheep fetal ovary autophagy is playing a role in cell survival, a finding in agreement with those of Gawriluk et al. in the mouse ovary (Gawriluk et al. 2011).

This discussion has largely focused on germ cell development. However, recruitment of granulosa cells during fetal development may play an important 
role in establishing the observed effects on fetal germ cell development and subsequently, the increased indicators of fertility in female offspring. It is interesting to note the classical pregranulosa cell marker LGR5 (Rastetter et al. 2014) was not differentially expressed at either day $55(q=0.5)$ or day $75(q=0.9)$. Many of the SDE genes are expressed in all cell types, including granulosa cells and pregranulosa cells. Therefore, direct effects of SDE genes on pregranulosa cells are possible. SDE oocyte genes also have the potential to affect the granulosa cells, with GDF9 (SDE at day 55) being a good example. The role of Notch-Jagged signaling in germ cell nest breakdown, recruitment of pregranulosa cells and follicle formation has been highlighted recently (Xu \& Gridley 2013, Zhao et al. 2016). Of further interest, the role of the disintergrin ADAM10 in Notch signaling and pregranulosa cell recruitment has also been reported (Feng et al. 2016), with expression of the oocyte-specific genes JAG1, GDF9, BMP15 and $N O B O X$ all being implicated in this process. In the current study, at day 75 , around the time of follicle formation, another disintergrin like gene, ADAMTS14, was upregulated ( 2.5 fold change, $q<0.01)$ in the fetal ovaries from dams exposed to restricted nutrition. Of the other genes implicated in pregranulosa cell recruitment via this mechanism, JAG1 (1.7 fold change, $q<0.01)$ and NOBOX $(2.1$ fold change, $q<0.01)$ are also upregulated, GDF9 shows a 1.6-fold upregulation $(q=0.05)$ and BMP15 expression is below the LLD. Thus, in the ovaries of day 75 fetuses from nutritionally restricted dams a pattern of gene expression exists with the potential to enhance pregranulosa cell recruitment and follicle formation.

In conclusion, this study demonstrates changes to the expression pattern of key genes in the fetal ovary following changes to maternal gestational nutrition. In a companion study, female offspring from this cohort of animals showed increased indicators of fertility. Of particular interest, upregulation of genes in fetal ovaries from dams exposed to restricted nutrition associated with NO production and metabolism as well as downregulation of protease inhibitor genes in the same fetal ovaries, offers insights into potential mechanisms whereby altered maternal gestational nutrition may affect fetal ovarian development and subsequently adult fertility.

Conceptually, we propose that the small number of significant fold changes observed in the day 55 fetal ovary transcriptome is a response to allow normal ovarian development in a reduced maternal nutritional environment. While changes to the fetal ovarian transcriptome are apparent at this age, morphological development of the ovary appears normal (ref companion paper). Following cessation of maternal nutritional restriction, we hypothesize gene expression gradually changes to levels consistent with the increased diet, as reflected by the smaller fold changes observed at day
75. It is during this window nutritional of change, (day 55-75) where ovarian gene expression is primed for low maternal nutrition, but the fetal ovary is exposed to high maternal nutrition, that changes to ovarian development are most likely to occur.

\section{Supplementary data}

This is linked to the online version of the paper at https://doi.org/10.1530/REP-18-0358.

\section{Declaration of interest}

The authors declare that there is no conflict of interest that could be perceived as prejudicing the impartiality of the research reported.

\section{Funding}

This work was supported by AgResearch SSIF funding and the Department of Anatomy, University of Otago.

\section{References}

Archibald AL, Cockett NE, Dalrymple BP, Faraut T, Kijas JW, Maddox JF, McEwan JC, Hutton Oddy V, Raadsma HW, Wade C et al. 2010 The sheep genome reference sequence: a work in progress. Animal Genetics 41 449-453. (https://doi.org/10.1111/j.13652052.2010.02100.x)

Asmad K, Kenyon PR, Pain SJ, Perera KC, Parkinson TJ, Lopez-Villalobos N \& Blair HT 2015 Effects of dam size and nutrition during pregnancy on fetal ovarian development of their offspring in sheep. Livestock Science 181 256-262. (https://doi.org/10.1016/j.livsci.2015.09.001)

Bebbere D, Ariu F, Bogliolo L, Masala L, Murrone O, Fattorini M, Falchi L \& Ledda S 2014 Expression of maternally derived KHDC3, NLRP5, OOEP and TLE6is associated with oocyte developmental competence in the ovine species. BMC Developmental Biology 14 1-13. (https://doi. org/10.1186/s12861-014-0040-y)

Bellingham M, Amezaga MR, Mandon-Pepin B, Speers CJB, Kyle CE, Evans NP, Sharpe RM, Cotinot C, Rhind SM \& Fowler PA 2013 Exposure to chemical cocktails before or after conception - the effect of timing on ovarian development. Molecular and Cellular Endocrinology $\mathbf{3 7 6}$ 156-172. (https://doi.org/10.1016/j.mce.2013.06.016)

Bonnet A, Cabau C, Bouchez O, Sarry J, Marsaud N, Foissac S, Woloszyn F, Mulsant P \& Mandon-Pepin B 2013 An overview of gene expression dynamics during early ovarian folliculogenesis: specificity of follicular compartments and bi-directional dialog. BMC Genomics 14 1-19. (https://doi.org/10.1186/1471-2164-14-1)

Borwick SC, Rhind SM, McMillen SR \& Racey PA 1997 Effect of undernutrition of ewes from the time of mating on fetal ovarian development in mid gestation. Reproduction, Fertility and Development 9 711-716. (https://doi.org/10.1071/R97011)

Broekmans FJ, Kwee J, Hendriks DJ, Mol BW \& Lambalk CB 2006 A systematic review of tests predicting ovarian reserve and IVF outcome. Human Reproduction Update 12 685-718. (https://doi.org/10.1093/ humupd/dml034)

Burney S, Caulfield JL, Niles JC, Wishnok JS \& Tannenbaum SR 1999 The chemistry of DNA damage from nitric oxide and peroxynitrite. Mutation Research/Fundamental and Molecular Mechanisms of Mutagenesis 424 37-49. (https://doi.org/10.1016/S0027-5107(99)00006-8)

Carbon S, Ireland A, Mungall CJ, Shu S, Marshall B, Lewis S, AmiGO Hub \& Web Presence Working Group 2009 AmiGO: online access to ontology and annotation data. Bioinformatics 25 288-289. (https://doi. org/10.1093/bioinformatics/btn615) 
Choi Y, Qin Y, Berger MF, Ballow DJ, Bulyk ML \& Rajkovic A 2007 Microarray analyses of newborn mouse ovaries lacking nobox. Biology of Reproduction 77 312-319. (https://doi.org/10.1095/ biolreprod.107.060459)

Clementi E 1998 Role of nitric oxide and its intracellular signalling pathways in the control of $\mathrm{Ca} 2$ homeostasis. Biochemical Pharmacology 55 713-718. (https://doi.org/10.1016/S0006-2952(97)00375-4)

Cooke JP $2003 \mathrm{NO}$ and angiogenesis. Atherosclerosis Supplements 4 53-60. (https://doi.org/10.1016/S1567-5688(03)00034-5)

Costa HF, Miguel MCV, Pedroso AM, Gobbo SP, Lopes FL, Peiro JR \& Nogueira GP 2014 Changing maternal nutrition in early pregnancy modifies fetal ovarian development in Nellcore cows. Reproduction, Fertility and Development 27 137-137. (https://doi.org/10.1071/ RDv27n1Ab88)

Da Silva-Buttkus P, van den Hurk R, te Velde ER \& Taverne MA 2003 Ovarian development in intrauterine growth-retarded and normally developed piglets originating from the same litter. Reproduction 126 249-258. (https://doi.org/10.1530/rep.0.1260249)

Da Silva P, Aitken RP, Rhind SM, Racey PA \& Wallace JM 2003 Effect of maternal overnutrition during pregnancy on pituitary gonadotrophin gene expression and gonadal morphology in female and male foetal sheep at day 103 of gestation. Placenta 24 248-257. (https://doi. org/10.1053/plac.2002.0897)

De Mees C, Bakker J, Szpirer J \& Szpirer C 2006 Alpha-fetoprotein: from a diagnostic biomarker to a key role in female fertility. Biomarker Insights 1 82-85. (https://doi.org/10.1177/117727190600100002)

Deng G, Royle G, Wang S, Crain K \& Loskutoff DJ 1996 Structural and functional analysis of the plasminogen activator inhibitor-1 binding motif in the somatomedin B domain of vitronectin. Journal of Biological Chemistry 271 12716-12723. (https://doi.org/10.1074/ jbc.271.22.12716)

Dobin A, Davis CA, Schlesinger F, Drenkow J, Zaleski C, Jha S, Batut P, Chaisson M \& Gingeras TR 2013 STAR: ultrafast universal RNAseq aligner. Bioinformatics 29 15-21. (https://doi.org/10.1093/ bioinformatics/bts635)

Escobar ML, Echeverría OM, Ortíz R \& Vázquez-Nin GH 2008 Combined apoptosis and autophagy, the process that eliminates the oocytes of atretic follicles in immature rats. Apoptosis 13 1253. (https://doi. org/10.1007/s10495-008-0248-z)

Fang FC \& Vazquez-Torres A 2002 Nitric oxide production by human macrophages: there's NO doubt about it. American Journal of Physiology: Lung Cellular and Molecular Physiology 282 L941-L943. (https://doi. org/10.1152/ajplung.00017.2002)

Feng L, Wang Y, Cai H, Sun G, Niu W, Xin Q, Tang X, Zhang J, Wang C, Zhang $\mathbf{H}$ et al. 2016 ADAM10-Notch signaling governs the recruitment of ovarian pregranulosa cells and controls folliculogenesis in mice. Journal of Cell Science 129 2202-2212. (https://doi.org/10.1242/ jcs.184267)

Fowler PA, Flannigan S, Mathers A, Gillanders K, Lea RG, Wood MJ, Maheshwari A, Bhattacharya S, Collie-Duguid ESR, Baker PJ et al. 2009 Gene expression analysis of human fetal ovarian primordial follicle formation. Journal of Clinical Endocrinology and Metabolism 94 1427-1435. (https://doi.org/10.1210/jc.2008-2619)

Fuentes E, Nadal A, Jacob R \& McNaughton P 1997 Actions of serum and plasma albumin on intracellular Ca2+ in human endothelial cells. Journal of Physiology 504 315-326. (https://doi.org/10.1111/j.14697793.1997.315be.x)

Gabant P, Forrester L, Nichols J, Van Reeth T, De Mees C, Pajack B, Watt A, Smitz J, Alexandre H, Szpirer C et al. 2002 Alpha-fetoprotein, the major fetal serum protein, is not essential for embryonic development but is required for female fertility. PNAS 99 12865-12870. (https://doi. org/10.1073/pnas.202215399)

Gawriluk TR, Hale AN, Flaws JA, Dillon CP, Green DR \& Rucker EB 2011 Autophagy is a cell survival program for female germ cells in the murine ovary. Reproduction 141 759-765. (https://doi.org/10.1530/REP-100489)

Gibellini L, De Biasi S, Pinti M, Nasi M, Riccio M, Carnevale G, Cavallini GM, Sala de Oyanguren FJ, O'Connor JE, Mussini C et al. 2012 The protease inhibitor atazanavir triggers autophagy and mitophagy in human preadipocytes. AIDS 26 2017-2026. (https://doi.org/10.1097/ QAD.0b013e328359b8be)
Grazul-Bilska AT, Caton JS, Arndt W, Burchill K, Thorson C, Borowczyk E, Bilski JJ, Redmer DA, Reynolds LP \& Vonnahme KA 2009 Cellular proliferation and vascularization in ovine fetal ovaries: effects of undernutrition and selenium in maternal diet. Reproduction 137 699-707. (https://doi.org/10.1530/REP-08-0375)

Gunn R, Sim D \& Hunter E 1995 Effects of nutrition in utero and in early life on the subsequent lifetime reproductive performance of Scottish Blackface ewes in two management systems. Animal Science $\mathbf{6 0}$ 223-230. (https://doi.org/10.1017/S1357729800008389)

Hefler LA, Reyes CA, O'Brien WE \& Gregg AR 2001 Perinatal development of endothelial nitric oxide synthase-deficient mice. Biology of Reproduction 64 666-673. (https://doi.org/10.1095/biolreprod64.2.666)

Heller R, Unbehaun A, Schellenberg B, Mayer B, Werner-Felmayer G \& Werner ER 2001 I-Ascorbic acid potentiates endothelial nitric oxide synthesis via a chemical stabilization of tetrahydrobiopterin. Journal of Biological Chemistry 276 40-47. (https://doi.org/10.1074/jbc. M004392200)

Hsu P-C, Liu M-Y, Hsu C-C, Chen L-Y \& Leon Guo Y 1998 Effects of vitamin $\mathrm{E}$ and/or $\mathrm{C}$ on reactive oxygen species-related lead toxicity in the rat sperm. Toxicology 128 169-179. (https://doi.org/10.1016/S0300483X(98)00068-7)

Ireland JLH, Scheetz D, Jimenez-Krassel F, Themmen APN, Ward F, Lonergan P, Smith GW, Perez GI, Evans ACO \& Ireland JJ 2008 Antral follicle count reliably predicts number of morphologically healthy oocytes and follicles in ovaries of young adult cattle. Biology of Reproduction $\mathbf{7 9}$ 1219-1225. (https://doi.org/10.1095/biolreprod.108.071670)

Ireland JJ, Smith GW, Scheetz D, Jimenez-Krassel F, Folger JK, Ireland JLH, Mossa F, Lonergan P \& Evans ACO 2010 Does size matter in females? An overview of the impact of the high variation in the ovarian reserve on ovarian function and fertility, utility of anti-Müllerian hormone as a diagnostic marker for fertility and causes of variation in the ovarian reserve in cattle. Reproduction, Fertility and Development 23 1-14. (https://doi.org/10.1071/RD10226)

Jameson SA, Natarajan A, Cool J, DeFalco T, Maatouk DM, Mork L, Munger SC \& Capel B 2012 Temporal transcriptional profiling of somatic and germ cells reveals biased lineage priming of sexual fate in the fetal mouse gonad. PLoS Genetics 8 e1002575. (https://doi.org/10.1371/ journal.pgen.1002575)

Jiang Y, Xie M, Chen W, Talbot R, Maddox JF, Faraut T, Wu C, Muzny DM, Li Y, Zhang W et al. 2014 The sheep genome illuminates biology of the rumen and lipid metabolism. Science 344 1168-1173. (https://doi. org/10.1126/science.1252806)

Joshi S, Davies H, Sims LP, Levy SE \& Dean J 2007 Ovarian gene expression in the absence of FIGLA, an oocyte-specific transcription factor. BMC Developmental Biology 7 67. (https://doi.org/10.1186/1471-213X-7-67)

Kalaany NY \& Mangelsdorf DJ 2006 LXRS and FXR: the Yin and Yang of cholesterol and fat metabolism. Annual Review of Physiology $\mathbf{6 8}$ 159-191. (https://doi.org/10.1146/annurev.physiol.68.033104.152158)

Kezele P \& Skinner MK 2003 Regulation of ovarian primordial follicle assembly and development by estrogen and progesterone: endocrine model of follicle assembly. Endocrinology 144 3329-3337. (https://doi. org/10.1210/en.2002-0131)

Kotsampasi B, Chadio S, Papadomichelakis G, Deligeorgis S, Kalogiannis D, Menegatos I \& Zervas G 2009 Effects of maternal undernutrition on the hypothalamic-pituitary-gonadal axis function in female sheep offspring. Reproduction in Domestic Animals 44 677-684. (https://doi. org/10.1111/j.1439-0531.2007.01046.x)

Krishna A \& Spanel-Borowski K 1989 Intracellular detection of albumin in the ovaries of golden hamsters by light and electron microscopy. Archives of Histology and Cytology 52 387-393. (https://doi.org/10.1679/ aohc.52.387)

Kwon H, Spencer TE, Bazer FW \& Wu G 2003 Developmental changes of amino acids in ovine fetal fluids. Biology of Reproduction $\mathbf{6 8}$ 1813-1820. (https://doi.org/10.1095/biolreprod.102.012971)

Kwon H, Ford SP, Bazer FW, Spencer TE, Nthanielsz PW, Nijland MJ, Hess BW \& Wu G 2004 Maternal undernutrition reduces concentrations of amino acids and polyamines in ovine fetal plasma and fluids. Biology of Reproduction 71 901-908. (https://doi.org/10.1095/ biolreprod.104.029645)

Law RH, Zhang Q, McGowan S, Buckle AM, Silverman GA, Wong W, Rosado CJ, Langendorf CG, Pike RN, Bird PI et al. 2006 An overview of 
the serpin superfamily. Genome Biology 7 216. (https://doi.org/10.1186/ gb-2006-7-5-216)

Lea RG, Andrade LP, Rae MT, Hannah LT, Kyle CE, Murray JF, Rhind SM \& Miller DW 2006 Effects of maternal undernutrition during early pregnancy on apoptosis regulators in the ovine fetal ovary. Reproduction 131 113-124. (https://doi.org/10.1530/rep.1.00844)

Lea RG, Amezaga MR, Loup B, Mandon-Pépin B, Stefansdottir A, Filis P, Kyle C, Zhang Z, Allen C, Purdie L et al. 2016 The fetal ovary exhibits temporal sensitivity to a 'real-life' mixture of environmental chemicals. Scientific Reports 6 22279. (https://doi.org/10.1038/srep22279)

Li H, Handsaker B, Wysoker A, Fennell T, Ruan J, Homer N, Marth G, Abecasis G \& Durbin R 2009 The sequence alignment/map format and SAMtools. Bioinformatics 25 2078-2079. (https://doi.org/10.1093/ bioinformatics/btp352)

Li Y, Ray D \& Ye P 2013 Identification of germ cell-specific genes in mammalian meiotic prophase. BMC Bioinformatics 14 1-13. (https:// doi.org/10.1186/1471-2105-14-S9-S1)

Long NM, Nijland MJ, Nathanielsz PW \& Ford SP 2010 The effect of early to mid-gestational nutrient restriction on female offspring fertility and hypothalamic-pituitary-adrenal axis response to stress. Journal of Animal Science 88 2029-2037. (https://doi.org/10.2527/jas.2009-2568)

Mailloux RJ, McBride SL \& Harper M-E 2013 Unearthing the secrets of mitochondrial ROS and glutathione in bioenergetics. Trends in Biochemical Sciences 38 592-602. (https://doi.org/10.1016/j. tibs.2013.09.001)

March KL, Wilensky RL, Roeske RW \& Hathaway DR 1993 Effects of thiol protease inhibitors on cell cycle and proliferation of vascular smooth muscle cells in culture. Circulation Research 72 413-423. (https://doi. org/10.1161/01.RES.72.2.413)

Mohamed BM, Verma NK, Davies AM, McGowan A, Crosbie-Staunton K, Prina-Mello A, Kelleher D, Botting $\mathrm{CH}$, Causey CP, Thompson PR et al. 2012 Citrullination of proteins: a common post-translational modification pathway induced by different nanoparticles in vitro and in vivo. Nanomedicine 7 1181-1195. (https://doi.org/10.2217/ nnm.11.177)

Mongia A, Bhaskaran M, Reddy K, Manjappa N, Baqi N \& Singhal PC 2004 Protease inhibitors modulate apoptosis in mesangial cells derived from a mouse model of HIVAN11 See Editorial by Foster, p. 1105. Kidney International 65 860-870. (https://doi.org/10.1111/j.15231755.2004.00464.x)

Murdoch W, Van Kirk E, Vonnahme K \& Ford S 2003 Ovarian responses to undernutrition in pregnant ewes, USA. Reproductive Biology and Endocrinology 1 1-8. (https://doi.org/10.1186/1477-7827-1-1)

Nanetti L, Vignini A, Moroni C, Pessina GP \& Mazzanti L 2004 LDL and HDL affect nitric oxide metabolism in human astrocytoma cells. Brain Research 1020. 173-177. (https://doi.org/10.1016/j. brainres.2004.06.026)

Napoli C, Paolisso G, Casamassimi A, Al-Omran M, Barbieri M, Sommese L, Infante T \& Ignarro LJ 2013 Effects of nitric oxide on cell proliferation. Journal of the American College of Cardiology 62 89-95. (https://doi.org/10.1016/j.jacc.2013.03.070)

Noël ES, Reis Md, Arain Z \& Ober EA 2010 Analysis of the albumin/ $\alpha$ fetoprotein/afamin/group specific component gene family in the context of zebrafish liver differentiation. Gene Expression Patterns 10 237-243.

Pautz A, Art J, Hahn S, Nowag S, Voss C \& Kleinert H 2010 Regulation of the expression of inducible nitric oxide synthase. Nitric Oxide 23 75-93. (https://doi.org/10.1016/j.niox.2010.04.007)

Preissner KT, May AE, Wohn KD, Germer M \& Kanse SM 1997 Molecular crosstalk between adhesion receptors and proteolytic cascades in vascular remodelling. Thrombosis and Haemostasis 78 88-95. (https:// doi.org/10.1055/s-0038-1657507)

Rae M, Palassio S, Kyle C, Brooks A, Lea R, Miller D \& Rhind S 2001 Effect of maternal undernutrition during pregnancy on early ovarian development and subsequent follicular development in sheep fetuses. Reproduction 122 915-922. (https://doi.org/10.1530/rep.0.1220915)

Rae MT, Kyle CE, Miller DW, Hammond AJ, Brooks AN \& Rhind SM 2002 The effects of undernutrition, in utero, on reproductive function in adult male and female sheep. Animal Reproduction Science 72 63-71. (https://doi.org/10.1016/S0378-4320(02)00068-4)

Rastetter RH, Bernard P, Palmer JS, Chassot A-A, Chen H, Western PS, Ramsay RG, Chaboissier M-C \& Wilhelm D 2014 Marker genes identify three somatic cell types in the fetal mouse ovary. Developmental Biology 394 242-252. (https://doi.org/10.1016/j.ydbio.2014.08.013)

Regassa A, Rings F, Hoelker M, Cinar U, Tholen E, Looft C, Schellander K \& Tesfaye D 2011 Transcriptome dynamics and molecular crosstalk between bovine oocyte and its companion cumulus cells. BMC Genomics 12 1-20. (https://doi.org/10.1186/1471-2164-12-1)

Rhind SM 2004 Effects of maternal nutrition on fetal and neonatal reproductive development and function. Animal Reproduction Science 82-83 169-181.

Rodrigues P, Limback D, McGinnis LK, Plancha CE \& Albertini DF 2009 Multiple mechanisms of germ cell loss in the perinatal mouse ovary. Reproduction 137 709-720. (https://doi.org/10.1530/REP-08-0203)

Safavi F \& Rostami A 2012 Role of serine proteases in inflammation: Bowman-Birk protease inhibitor $(\mathrm{BBI})$ as a potential therapy for autoimmune diseases. Experimental and Molecular Pathology 93 428-433. (https://doi.org/10.1016/j.yexmp.2012.09.014)

Sawyer HR, Smith P, Heath DA, Juengel JL, Wakefield SJ \& McNatty KP 2002 Formation of ovarian follicles during fetal development in sheep. Biology of Reproduction 66 1134-1150. (https://doi.org/10.1095/ biolreprod66.4.1134)

Seralini GE, Lafaurie M, Krebs B \& Stora C 1986 Alphafetoprotein and atretic follicles in the ovary of the pregnant rat. Tumour Biology 7 1-8.

Shini S \& Kaiser P 2009 Effects of stress, mimicked by administration of corticosterone in drinking water, on the expression of chicken cytokine and chemokine genes in lymphocytes. Stress 12 388-399. (https://doi. org/10.1080/10253890802526894)

Soh YQS, Junker JP, Gill ME, Mueller JL, van Oudenaarden A \& Page DC 2015 A gene regulatory program for meiotic prophase in the fetal ovary. PLOS Genetics 11 e1005531. (https://doi.org/10.1371/journal. pgen.1005531)

Sram RJ, Binkova B \& Rossner P 2012 Vitamin C for DNA damage prevention. Mutation Research/Fundamental and Molecular Mechanisms of Mutagenesis 733 39-49. (https://doi.org/10.1016/j. mrfmmm.2011.12.001)

Tamir S, Burney S \& Tannenbaum SR 1996 DNA damage by nitric oxide. Chemical Research in Toxicology 9 821-827. (https://doi.org/10.1021/ tx9600311)

Thomas GB, McNeilly AS \& Brooks AN 1993 Development of gonadotrophs and thyrotrophs in the female foetal sheep pituitary: immunocytochemical localization studies. Journal of Neuroendocrinology 5 157-161. (https:// doi.org/10.1111/j.1365-2826.1993.tb00376.x)

Törmälä R-M, Jääskeläinen M, Lakkakorpi J, Liakka A, Tapanainen JS \& Vaskivuo TE 2008 Zona pellucida components are present in human fetal ovary before follicle formation. Molecular and Cellular Endocrinology 289 10-15. (https://doi.org/10.1016/j.mce.2008.01.029)

Trapnell C, Roberts A, Goff L, Pertea G, Kim D, Kelley DR, Pimentel H, Salzberg SL, Rinn JL \& Pachter L 2012 Differential gene and transcript expression analysis of RNA-seq experiments with TopHat and Cufflinks. Nature Protocols 7 562-578. (https://doi.org/10.1038/nprot.2012.016)

Tsujimoto Y \& Shimizu S 2000 Another way to die: autophagic programmed cell death. Cell Death and Differentiation 12 1528-1534. (https://doi. org/10.1038/sj.cdd.4401777)

Vosatka RJ, Hassoun PM \& Harvey-Wilkes KB 1998 Dietary I-arginine prevents fetal growth restriction in rats. American Journal of Obstetrics and Gynecology $178 \quad 242-246 . \quad$ (https://doi.org/10.1016/S00029378(98)80007-0)

Wendehenne D, Pugin A, Klessig DF \& Durner J 2001 Nitric oxide: comparative synthesis and signaling in animal and plant cells. Trends in Plant Science 6 177-183. (https://doi.org/10.1016/S13601385(01)01893-3)

Wu G, Pond WG, Flynn SP, Ott TL \& Bazer FW 1998 Maternal dietary protein deficiency decreases nitric oxide synthase and ornithine decarboxylase activities in placenta and endometrium of pigs during early gestation. Journal of Nutrition 128 2395-2402. (https://doi. org/10.1093/jn/128.12.2395)

Wu G, Bazer FW, Cudd TA, Meininger CJ \& Spencer TE 2004 Maternal nutrition and fetal development. Journal of Nutrition 134 2169-2172. (https://doi.org/10.1093/jn/134.9.2169)

Xu J \& Gridley T 2013 Notch2 is required in somatic cells for breakdown of ovarian germ-cell nests and formation of primordial follicles. BMC Biology 11 13. (https://doi.org/10.1186/1741-7007-11-13) 
Zhang J 2007 The mouse oocyte as a model in reproductive toxicology studies. In Institute of Environmental Medicine.

Zhang W, Wei Q-W, Wang Z-C, Ding W, Wang W \& Shi F-X 2011 Cellspecific expression and immunolocalization of nitric oxide synthase isoforms and the related nitric oxide/cyclic GMP signaling pathway in the ovaries of neonatal and immature rats. Journal of Zhejiang University Science B 12 55-64. (https://doi.org/10.1631/jzus.B1000174)

Zhao L, Du X, Huang K, Zhang T, Teng Z, Niu W, Wang C \& Xia G 2016

Rac1 modulates the formation of primordial follicles by facilitating STAT3-directed Jagged1, GDF9 and BMP15 transcription in mice. Scientific Reports 6 23972. (https://doi.org/10.1038/srep23972)
Zheng Q \& Wang X-J 2008 GOEAST: a web-based software toolkit for gene ontology enrichment analysis. Nucleic Acids Research 36 W358-W363. (https://doi.org/10.1093/nar/gkn276)

Received 11 July 2018

First decision 31 August 2018

Revised manuscript received 1 October 2018

Accepted 11 October 2018 